\title{
A Sentinel-1 Based Processing Chain for Detection of Cyclonic Flood Impacts
}

\author{
Cyprien Alexandre ${ }^{1, *}$, Rosa Johary ${ }^{2}$, Thibault Catry ${ }^{3}$, Pascal Mouquet ${ }^{1}$, \\ Christophe Révillion ${ }^{1}{ }^{(1)}$, Solofo Rakotondraompiana ${ }^{2}$ and Gwenaelle Pennober ${ }^{1}$ \\ 1 UMR 228 Espace-Dev, SEAS-OI, 97410 Saint-Pierre, Reunion Island, France; pascal.mouquet@ird.fr (P.M.); \\ christophe.revillion@univ-reunion.fr (C.R.); gwenaelle.pennober@univ-reunion.fr (G.P.) \\ 2 IOGA, Institut et Observatoire Géophysique d'Antananarivo, Antananarivo 101, Madagascar; \\ rosajohar@gmail.com (R.J.); srakotondraompiana@gmail.com (S.R.) \\ 3 UMR 228 Espace-Dev, Maison de la télédétection, 34090 Montpellier, France; thibault.catry@ird.fr \\ * Correspondence: cyprien.alexandre@ird.fr
}

Received: 29 November 2019; Accepted: 8 January 2020; Published: 10 January 2020

\begin{abstract}
In the future, climate change will induce even more severe hurricanes. Not only should these be better understood, but there is also a necessity to improve the assessment of their impacts. Flooding is one of the most common powerful impacts of these storms. Analyzing the impacts of floods is essential in order to delineate damaged areas and study the economic cost of hurricane-related floods. This paper presents an automated processing chain for Sentinel- 1 synthetic aperture radar (SAR) data. This processing chain is based on the S1-Tiling algorithm and the normalized difference ratio (NDR). It is able to download and clip S1 images on Sentinel-2 tiles footprints, perform multi-temporal filtering, and threshold NDR images to produce a mask of flooded areas. Applied to two different study zones, subject to hurricanes and cyclones, this chain is reliable and simple to implement. With the rapid mapping product of EMS Copernicus (Emergency Management Service) as reference, the method confers up to $95 \%$ accuracy and a Kappa value of 0.75 .
\end{abstract}

Keywords: hurricane; cyclone; flood; Sentinel 1 time series; change detection; NDR; SAR

\section{Introduction}

Remote sensing has emerged as a privileged means of observing and studying natural disasters. The capabilities of spaceborne sensors and platforms allow more accurate and frequent observations. Optical imagery, usually preferred because of its accessibility, is often unusable because of the bad weather conditions caused by the extreme weather events inducing natural disasters. As evidenced by the increasing number of satellites launched between 2007 and 2019 [1], synthetic aperture radar (SAR) imagery is becoming more and more popular. The numerous images produced offer new opportunities to be exploited in the field of natural hazards. Radar images are less impacted than optical imagery by cloudiness and the active sensor system allows for night-time snapshots [2].

Processing chains are algorithms developed for the automated extraction of information from more or less raw data. Freely shared and documented, such algorithms represent a way to continue the desire to democratize the access and use of SAR images. Automation is a way to deliver end-products that are easy to handle for users with no expertise in SAR imagery, often considered extremely complex. Developing and making available such processing chains and products, in order to study the damage related to natural disasters, is a powerful tool for educating exposed populations, informing the affected territories, and helping the region to assess the risks with crisis management and planning.

Multiple long-term climate analysis predicts stagnation or a slight decrease in the number of tropical cyclones worldwide, with a probable displacement towards the poles of their trajectories $[3,4]$. 
The South West Indian Ocean (SWIO) experienced nine cyclones per year on average during the last six decades, among which 0.8 per year made landfall over Mozambique coasts. During a comparable period 5.1 events made landfall per year in the North Atlantic Ocean coasts [5]. No significant changes in frequency could be highlighted for both regions during this period, but future impacts for populations could increase as there is a large global consensus on cyclone intensity predictions (maximum intensity reached for a cyclone, number of cyclones reaching high intensities, frequency of landfalls for high intensity cyclones) [6]. Recent emergence of category 5 cyclones in the SWIO even if no significant increase in frequency could have been established, is a major concern for populations and economics, as damages could increase significantly [7].

Floods are one of the most common and stronger impacts of hurricanes. According to Revilla-Romero et al. [8], they are globally among the most catastrophic natural disasters in terms of the impact on both human life and the economy. Because of the large areas impacted and the need for rapid availability of geographical products for crisis management and field actions, remote sensing is an adapted method for flood detection. Floods are widely studied and mapped using different remote sensing techniques.

Optical sensors are commonly used because of their simple interpretability, but are strongly affected by atmospheric disturbance. Cloud cover during the days around the event is usually significant. Synthetic aperture radar (SAR) sensors offer less sensitivity to cloud cover, allowing for a better frequency of images [9]. Hence, SAR is widely used for mapping water and flooded areas [8,10-14]. New satellites such as the Sentinel constellation and particularly Sentinel-1 A and B (launched in 2014 and 2016 respectively) provide interesting repetitiveness to measure the impact of natural disasters and study the resilience of environments through time series. Thus, change detection based on multi-temporal SAR images is increasingly used for disaster monitoring [10,15-17], especially for flood events [18].

Different flood detection methods are based on SAR imagery. We will differentiate between the methods of textural analysis, spectral analysis, and change detection. Zhang et al. [19] proposed a learning textural approach which is efficient but requires a training set in the procedure. Gong et al. [20] used Gabor filters for SAR classification as they have strong discriminating power in classification problems. However, Gabor-based approaches have the disadvantages of being complex and extremely disturbed by the noise in SAR images, and selecting proper features is usually difficult and time consuming. Sghaier et al. [21] used a textural and data fusion analysis on SAR time series (Radarsat-2 and Sentinel-1) to map floods in Canada, Greece and Iran. They compared their results with some other studies and showed that their texture-based approach achieves better accuracy in the case of flood detection than methods based on change detection and thresholding. This approach is however much more complicated and time-consuming to implement than change detection approaches.

Spectral analysis has been used in many previous studies on Sentinel-1 images thanks to pixel or object-based method in order to map surface water and floods. Twele et al. [22] developed a fully automatic chain for the processing of Sentinel-1 ground range detected (GRD backscattering) based on thresholding, fuzzy-logic-based classification refinement, final classification, including auxiliary data, and dissemination of the results that can be achieved using a web-based platform. Li et al. [23] used a change detection approach on Sentinel-1 GRD data to develop an efficient method for rapid flood mapping with low processing times. Although fully automated, this method depends on the selection of a reference image and the authors underline that this step can be time consuming (several hours might be required). Amitrano et al. [24] provided a unsupervised framework for Sentinel-1 flood mapping combining a textural analysis with a fuzzy classification on GRD amplitudes and a change detection approach, designed for end users and decision makers. Zhang et al. [25] estimated the impact of hurricane Irma on Florida in terms of floods using both spectral analysis and InSAR from Sentinel-1 data to quantify the extent of the floods and water level variations. In Bayik et al. [26] flooded areas were extracted with threshold, random forest and deep learning approaches on Sentinel-1 time-series at the border of Turkey and Greece. 
Algebraic methods are simple combinations of images and polarization between pre- and post-event. Difference, introduced by Weismiller et al. [27], is the most straightforward algebraic method. Ratio methods are commonly used in SAR imagery for change detection. According to Rignot and van Zyl [28], the ratio method is more effective for minimizing speckle noise. Normalized difference change detection (NDCD), introduced by Gianinetto and Villa [29], demonstrates good performance for flood detection. Based on normalized difference reflectance (NDR), the NDCD can be used with different products and polarization combinations. More complex methods such as image transformations (principal component analysis (PCA) [30], multivariate alteration detection (MAD) [31]), or different classification methods, pixel or object based [32-34], have also been developed for change detection with SAR data.

In order to automate SAR data processing, the normalized difference method has been chosen for its simplicity, robustness and algorithm speed. It is easily reproducible and is simple to transfer to non-expert users. It was applied to Sentinel-1 images, in order to take advantage of high spatial resolution $(10 \mathrm{~m})$, and high temporal revisit (12 days).

This paper will introduce the step-by-step construction of a processing chain dedicated to flood detection using Sentinel-1 SAR multi-temporal data, from the downloading of the data to the production of a map of flooded areas based on a change detection approach.

\section{Materials and Methods}

\subsection{Study Area}

In order to determine if this method is efficient in different spatial contexts, we focused our study on the city of Marsh Harbour on Great Abaco, one in the Bahamas in the northern Caribbean (West Atlantic, Figure 1), and Beira on the Mozambique coast (East Africa, Figure 2), two regions impacted by expetional hurricanes and cyclones in 2019 , and both radically different.

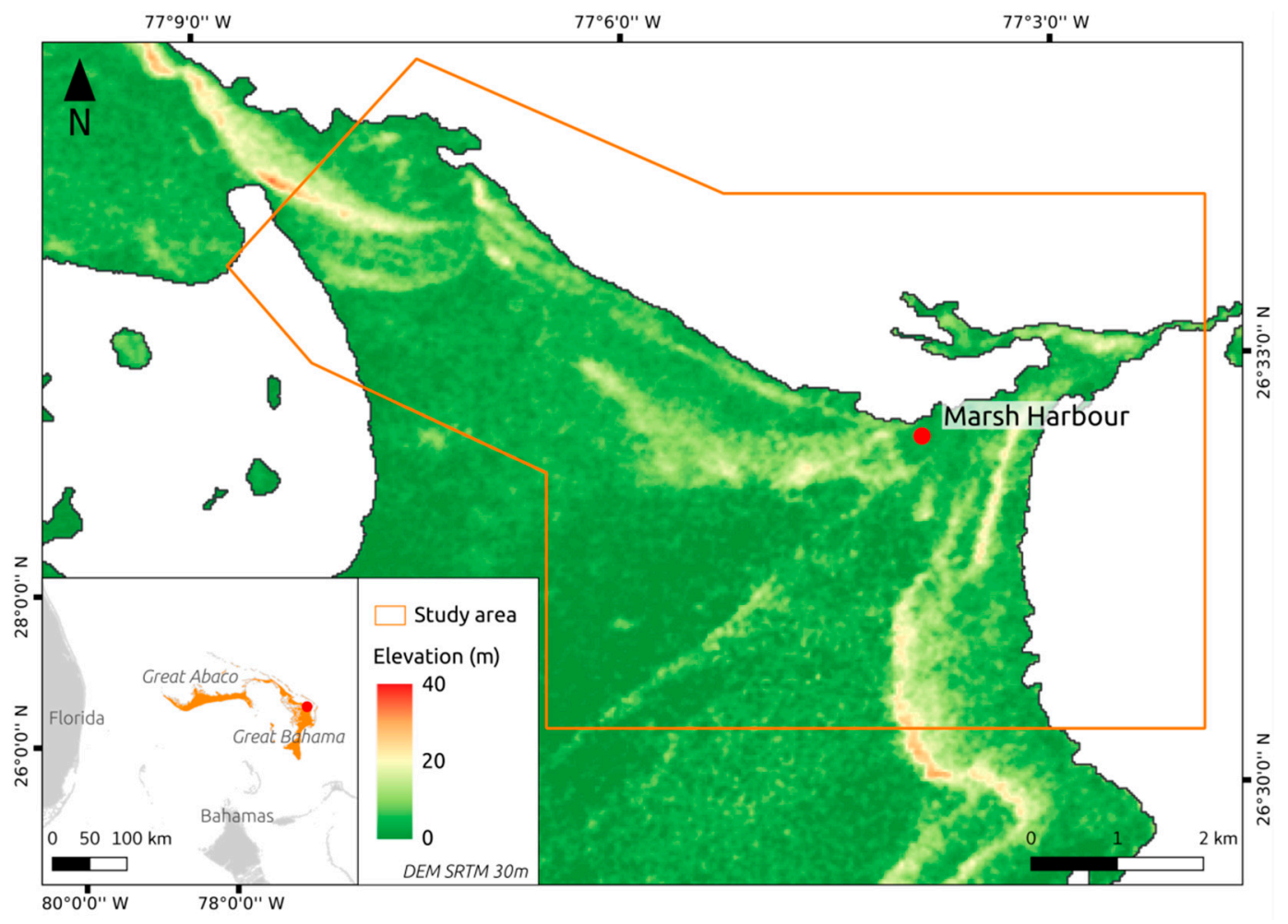

Figure 1. Localization map of Great Bahama and Great Abaco with elevation of study area. Altimetry from NASA Shuttle Radar Topography Mission Digital Elevation Model (SRTM DEM). 


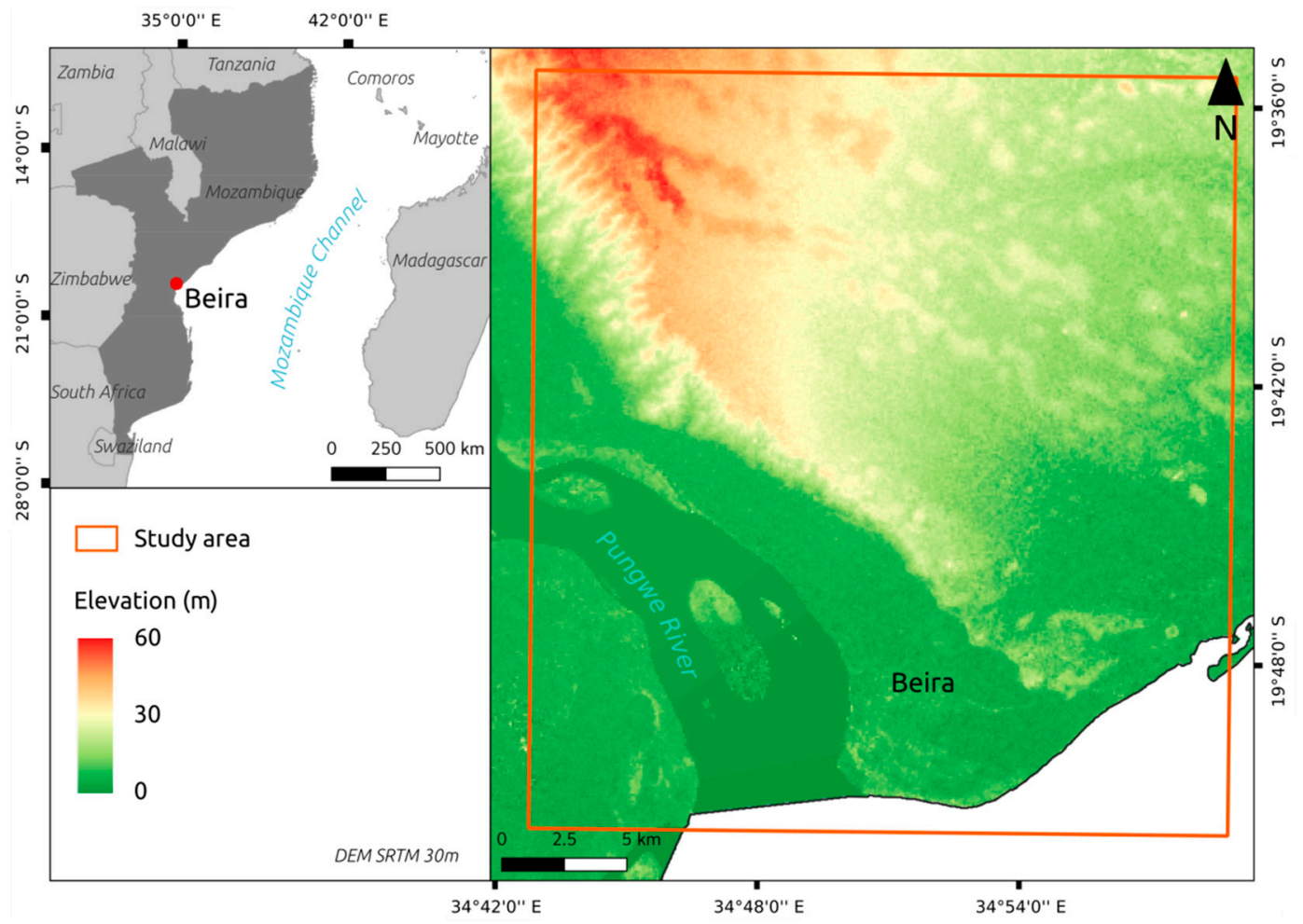

Figure 2. Location of the city of Beira, on the central eastern coast of Mozambique, facing the Mozambique Channel.

Great Abacos is located by $26^{\circ}$ North and $77^{\circ}$ West between the Atlantic Ocean and the Caribbean. The island is a combination of coral formations and relatively flat limestone which a large portion reaches an elevation of no more than a few meters, the highest point reaching 42 meters in altitude [35]. The hurricane season lasts from June to November with a peak from mid-August to late November [36]. The majority of GDP $(40 \%)$ comes from the tourism economy and the human development index (HDI) is one of the highest in the world ( 0.807 and 54th in the world).

Mozambique is a country on the southeast coast of the African continent facing Madagascar. It is bordered by South Africa and Tanzania to the north. After 16 years (1977-1992) of civil war, Mozambique is now experiencing strong economic growth, but its HDI (0.437) is one of the lowest in the world, placing the country 180th out of 189. The cyclonic season in SWIO lasts from November to April with a peak in January and February.

\subsubsection{Marsh Harbour, Great Abaco, Bahamas (Dorian)}

Marsh Harbour is located at the east of Abaco Island (Figure 1). Most of the housing is located in the northern part of the study area, near the ocean (Figure 3). Marsh Harbour is the fifth largest city in the bahamas with a population of 6283 as of 2012.

The eye of Hurricane Dorian reached the Bahamas on 1 September 2019 with maximum sustained winds of $297 \mathrm{~km} / \mathrm{h}$. Even if the Caribbean regularly experiences hurricanes, Dorian was qualified as the strongest event on record ever to hit the Bahamas. It impacted the region in different ways: extensive loss of vegetation (leaves and aerial parts burnt by the salt or stripped by the wind), damaged buildings and infrastructures, and large areas of flooding or submersion as a consequence of precipitation and sea level surge in the lower parts of the islands (WMO, World Meteorological Organization) [37]. The area is characterized by flat land and the absence of major rivers. The main risk of flooding is therefore related to marine submersion and rainwater.

This location in the Bahamas was chosen as a calibration site for the development of the methodology. Despite the relative absence of recent and accurate ground truth data, the extensive 
media coverage provided us with a great amount of aerial and field photos and videos of the impacted areas, which could be used to determine threshold values for flood detection (Section 2.3.3).

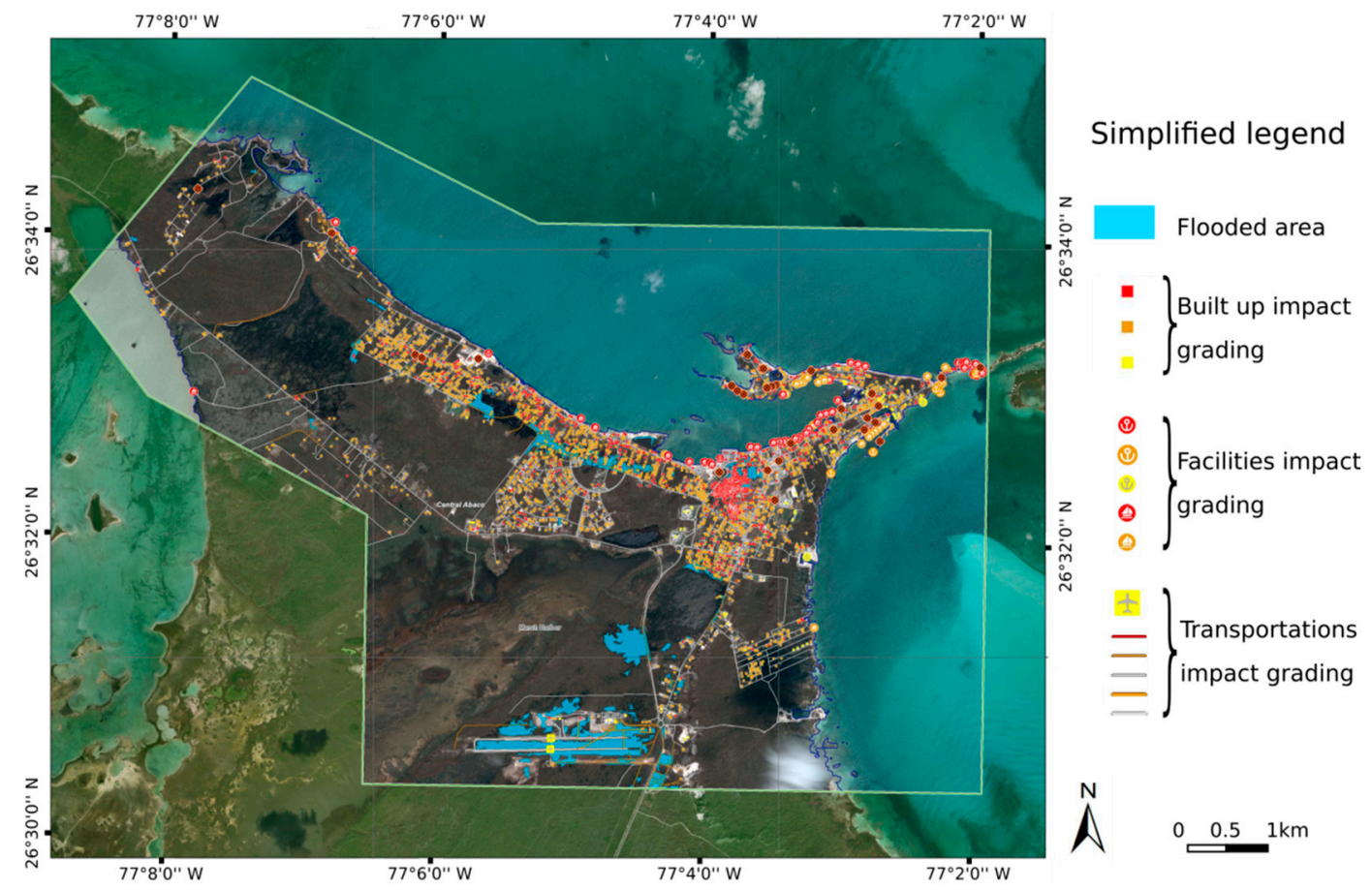

Figure 3. Simplified EMSR385 map from the full-resolution original Copernicus product.

\subsubsection{Beira, Mozambique (Idai)}

Beira is a coastal city in the Mozambique channel located on Buzi Rivers and Pungwe Rivers delta in the central region of Mozambique. This city is one of the fastest growing economic centers in the state. It holds the regionally significant Port of Beira, which acts as a gateway for both the central interior portion of the country as well as the land-locked nations of Zimbabwe, Zambia, and Malawi (mining corridor). Beira's population is currently over 500,000 and is growing fast. The wealthiest population is located on the hills, while slums are the most affected by the floods.

Cyclone Idai hit Mozambique twice, first on 4 March 2019 as a tropical depression, and then, after a few days reinforcing in the Mozambique Channel, Idai made landfall close to the city of Beira on 14 March at its maximum intensity, with heavy rainfall and strong winds of $165 \mathrm{~km} / \mathrm{h}$ gusting up to $230 \mathrm{~km} / \mathrm{h}$ (RSMC La Réunion, Regional Specialized Meteorological Center) [38]. This tropical cyclone caused massive floods and heavy damage in Mozambique, claiming over 600 lives (WMO, World Meteorological Organization) [39]. This delta area is exposed to flooding by the overflow of the Pungwe River and other minor rivers near the city.

\subsection{Data}

Sentinel-1 SAR images have been used for this study. Sentinel-1 is a constellation of two polar-orbiting satellites (S1A-B) from the European Space Agency (ESA), performing C-band synthetic aperture radar imaging. Sentinel-1 data acquisitions began in 2014 with the launch of the first satellite. Since April 2016 the two satellites permit a revisit of each point on the globe every 6 days. This repetitiveness, the resolution of the data and their free access make it a very interesting data to work on the impact of natural disaster. The products selected are level 1 GRD, VV+VH.

We selected images with the least speckle, and which were nearest to the acquisition time of Sentinel-2 images for comparison of results (see Table 1 for details of the images used). 
Table 1. Dates of the images used in both study areas.

\begin{tabular}{|c|c|c|c|c|}
\hline Site & Image order & Sentinel-1 & Sentinel-2 & Pléiade/GeoEye \\
\hline Marsh Harbour (Great & Pre-event & 21 August 2019 & & 4 December 2018 \\
\hline Abaco, Bahamas) & Post-event & 2, 8, 14 September 2019 & & 5 September 2019 \\
\hline Beira (Mozambique) & Pre-event & 18 February 2019 & 2 December 2018 & \\
\hline
\end{tabular}

\subsection{Methods}

\subsubsection{General Framework}

The general processing chain uses S1-Tiling to download and pre-process Sentinel-1 images. Python algorithms are used to generate NDR, smoothing and thresholding (Figure 4). These scripts can be fully chained to automate multiple tiles processing and enable flood detection over a full time series. A direct comparison between products is possible as they are orthorectified and clipped to the same S2 footprints. Details of the methodology are presented in the following sections.

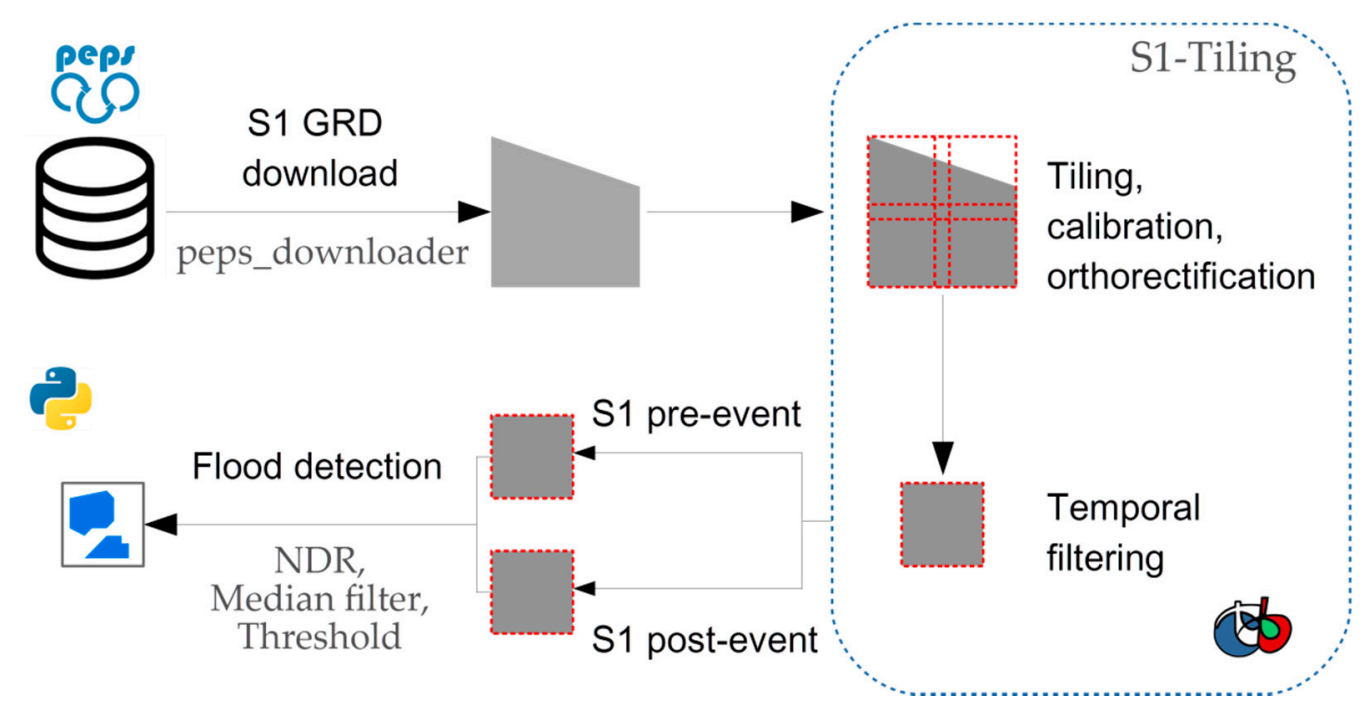

Figure 4. General framework of the processing chain.

\subsubsection{Sentinel-1 Pre-Processing (S1-Tiling)}

Sentinel-1 images were downloaded and pre-processed using the S1-Tiling [40] processing chain developed by the CNES (France's Centre National d'Etudes Spatiales) in collaboration with the Cesbio (Centre d'Etudes Spatiales de la Biosphère, Toulouse, France). It allows the user to (i) automatically download Sentinel-1 images, (ii) clip them to Sentinel-2 tiles, (iii) ortho-rectify the S1 scenes and (iv) perform a multi-temporal filtering of the S1 images. Except for the multi-temporal filter part, this program is fully coded in Python.

Sentinel-1 images are downloaded from the PEPS (Plateforme d'Exploitation des Produits Sentinel) server of the CNES thanks to the peps_download [41] program, using different parameters such as date, satellite or spatial extent (for example, the extent of Sentinel-2 tiles).

Clipping Sentinel-1 images to Sentinel-2 tiles allows the user to work easily with cross products and facilitates future applications using both radar and optical images from the Sentinel constellation. Orthorectification is done using global topographic data generated from National Aeronautics and Space Administration (NASA) Shuttle Radar Topography Mission (SRTM) acquired in 2000 and released in 2015. Spatial resolution of SRTM data is $30 \mathrm{~m}$ [35].

Images were then filtered thanks to a large time-series before the event to reduce granular speckle noise using a multi-temporal filter based on Quegan method [42]. Multi-temporal filtering methods 
combines time series images acquired on the same area to reduce speckle while preserving spatial information. Filtering is performed with the Orfeo ToolBox non-official plugin developed by the creator of S1-Tiling.

\subsubsection{Normalized Difference Ratio}

The principle of normalized difference change detection (NDCD) or Normalized Difference Ratio (NDR) is developed respectively in Gianinetto and Villa [29] and Mishra and Susaki [43]. This method is a normalized form of a ratio between pre- and post-event images. NDR is defined as:

$$
\mathrm{NDR}=\frac{\mathrm{Y}_{2}-\mathrm{Y}_{1}}{\mathrm{Y}_{2}+\mathrm{Y}_{1}}
$$

where $Y_{1}$ et $Y_{2}$ represent pre-event and post-event images respectively.

The NDR values range between -1 and +1 , which represent the maximum reflectance decrease and increase respectively. A 0 value means no change.

According to different studies $[12,44,45]$, cross-polarization images seem to be the best products to differentiate water from soil, especially in the context of rapid mapping. Both VV and VH polarizations will be used here.

The NDR image is then binarized in order to keep only the lowest values, meaning a strong decrease of the backscattered signal which may be associated with the appearance of water. This step is done by a simple thresholding of the NDR, values below are classified as water.

The lack of field data available compelled us to find other solutions in order to define the threshold below which we consider the pixel as representing a flooded area. On Marsh Harbour, the threshold could be determined empirically by comparing NDR values with aerial video footages of media coverage (as seen in Clement et al. [46]) just the day after the cyclone hit. By reporting visible water limits on the aerial images to the NDR image, we could determine that the threshold value of -0.2 was the most spatially compliant with the flooded areas. In order to maintain coherence in the study protocol, the same threshold was chosen for the second study area of Beira.

There are two ways to process NDR through the chain. Firstly, this can be done by chronological pairs. NDR is computed for each pair of consecutive images for a date range specified by the user. This method allows good detection of the maximum change date in a period of time. Secondly, NDR can be processed using a reference date. This method consists of processing NDR between a reference pre-event date, ideally acquired in dry weather, and one by one, all the other images included in the date range. This method is very useful for studying the resilience of the area, i.e., its capacity to return (or not) to its initial state.

\subsubsection{Data Validation and Comparison}

The final product will be compared to other results from an operational change detection method. EMS (emergency management service) of Copernicus (the European Union's Earth observation program) proposes different damage maps for crisis management (Rapid Mapping) of many events including hurricanes. They use SAR and optical images, depending on availability.

Rapid mapping of Marsh Harbour (EMSR385; Figure 3) uses high spatial resolution imagery with a Pléiades pre-event image from 4 December 2018 and a post-event image from Geoeye on 5 September 2019.

Rapid mapping of Beira (EMSR348; Figure 5) was produced using the Sentinel satellite constellation with a pre-event Sentinel-2 from 2 December 2018, and a Sentinel-1 post-event from 20 March 2019.

Flooded areas from EMS rapid mapping will be considered as ground-truth (actual) and flooded areas detected by NDR (predicted) will be compared to them. A confusion matrix will be built to calculate the statistical indicators necessary to evaluate the results of the flood detection method used (Table 2). 


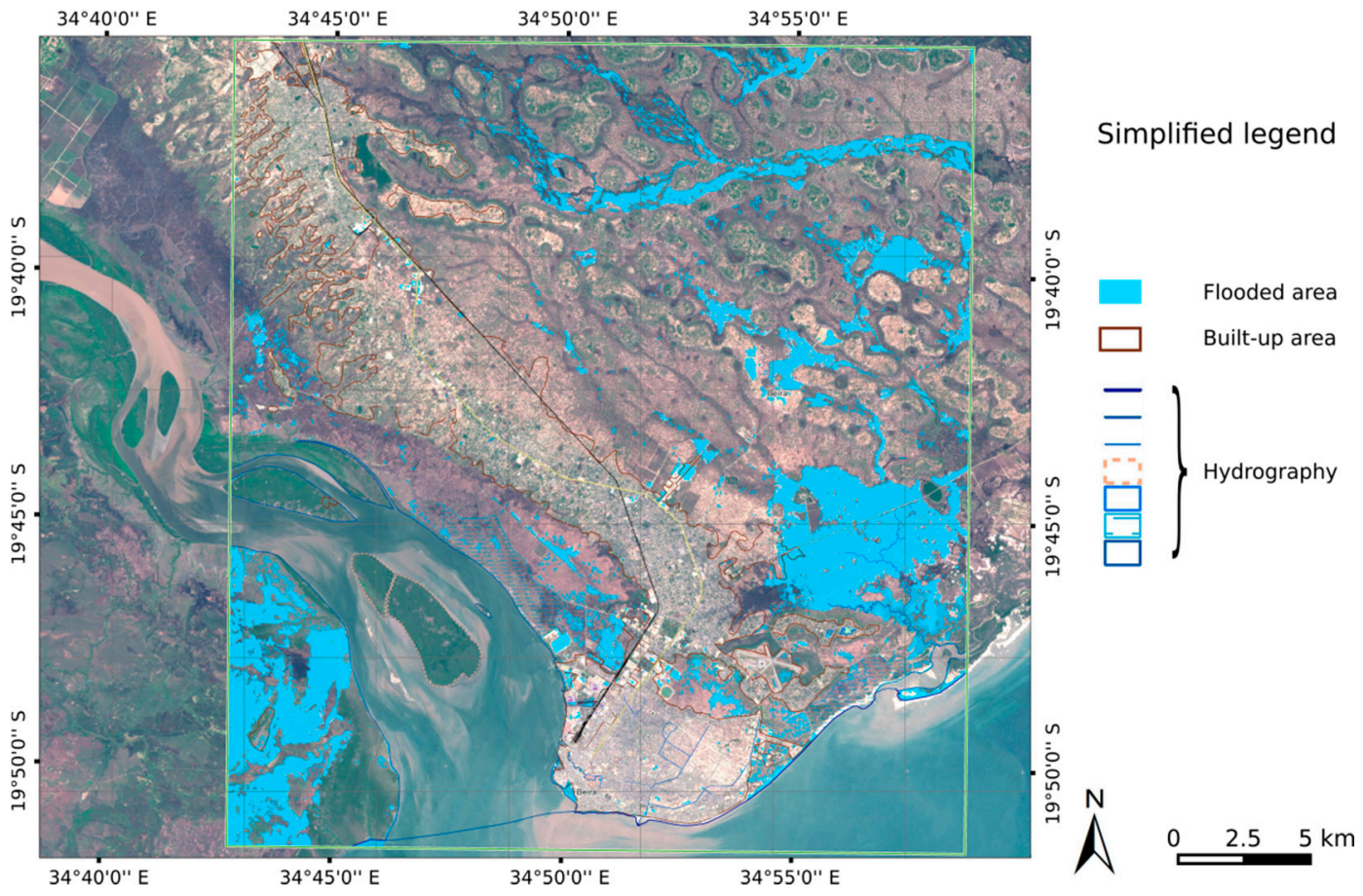

Figure 5. Simplified EMSR348 map from the full-resolution original Copernicus product.

Table 2. Confusion matrix description.

\begin{tabular}{ccc}
\hline Observed & Predicted Flooded & Predicted Non-Flooded \\
\hline Actual flooded & $\mathrm{TP}^{1}$ & $\mathrm{FN}$ \\
Actual non-flooded & $\mathrm{FP}$ & $\mathrm{TN}$
\end{tabular}

${ }^{1}$ TP: True Positive (predicted flooded and actually flooded), TN: True Negative (predicted non- flooded and actually non-flooded), FP:False Positive (predicted flooded but actually non-flooded) and FN: False Negative (predicted non-flooded but actually flooded).

The Kappa index [47] (K) will be calculated thanks to the confusion matrix presented. $\mathrm{K}$ is a coefficient of agreement for nominal scales. This index is recognized as reliable for classification evaluation because it integrates false positives and false negatives into its agreement calculation through the probability of random agreement. F1-score is also mentioned in the literature, but it is less adapted for binary values.

Accuracy and Kappa index will be calculated to evaluate the flood detection as:

(1) The observed agreement rate or accuracy:

$$
\mathrm{P}_{\mathrm{O}}=\frac{\mathrm{TP}+\mathrm{TN}}{\text { Total }}
$$

(2) The probability of flooded $\left(\mathrm{P}_{\mathrm{f}}\right)$, non-flooded $\left(\mathrm{P}_{\mathrm{nf}}\right)$ and the probability of random agreement $\left(\mathrm{P}_{\mathrm{e}}\right)$ :

$$
\begin{gathered}
\mathrm{P}_{\mathrm{f}}=\frac{(\mathrm{TP}+\mathrm{FN}) \times(\mathrm{TP}+\mathrm{FP})}{\mathrm{Total}^{2}} \\
\mathrm{P}_{\mathrm{nf}}=\frac{(\mathrm{FN}+\mathrm{TN}) \times(\mathrm{FP}+\mathrm{TN})}{\text { Total }^{2}} \\
\mathrm{P}_{\mathrm{e}}=\mathrm{P}_{\mathrm{f}}+\mathrm{P}_{\mathrm{nf}}
\end{gathered}
$$


(3) Cohen's Kappa:

$$
\mathrm{K}=\frac{\mathrm{P}_{\mathrm{o}}-\mathrm{P}_{\mathrm{e}}}{1-\mathrm{P}_{\mathrm{e}}}
$$

Kappa values are to be interpreted as follows:
a. $\quad<0.01 \rightarrow$ no agreement
b. $\quad 0.01-0.20 \rightarrow$ slight agreement
c. $\quad 0.21-0.40 \rightarrow$ fair agreement
d. $\quad 0.41-0.60 \rightarrow$ moderate agreement
e. $\quad 0.61-0.80 \rightarrow$ substantial agreement
f. $\quad 0.81-1.00 \rightarrow$ almost perfect agreement.

\section{Results}

\subsection{Bahamas}

In the Marsh Harbour area, the NDR is calculated from images of 21 August, ten days before the event, and 2 September, the day after the event (Figure 6). This short time difference between acquisitions allows elimination of all potential variations which could be due to other sensitive micro-events like tropical rain.

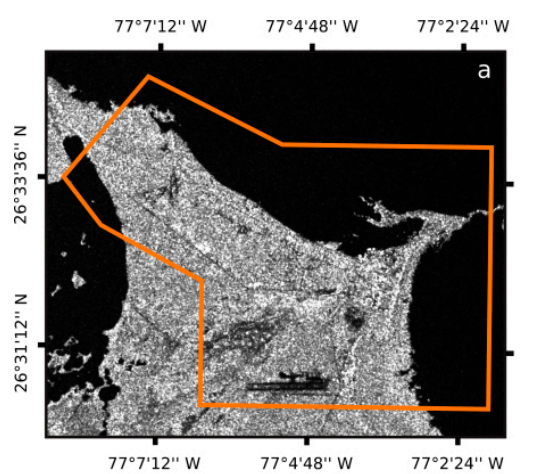

EMS Copernicus EMSR 385 study area
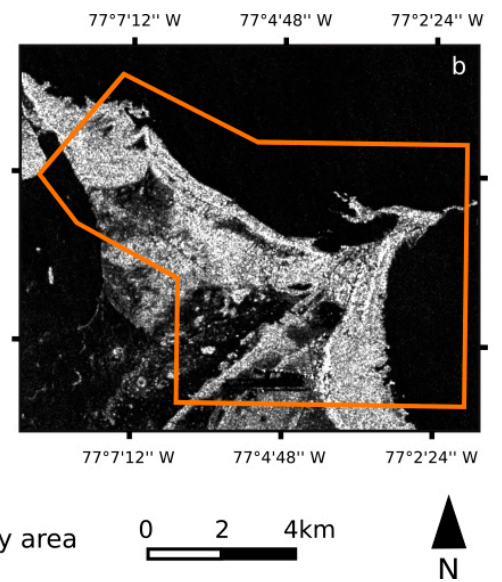

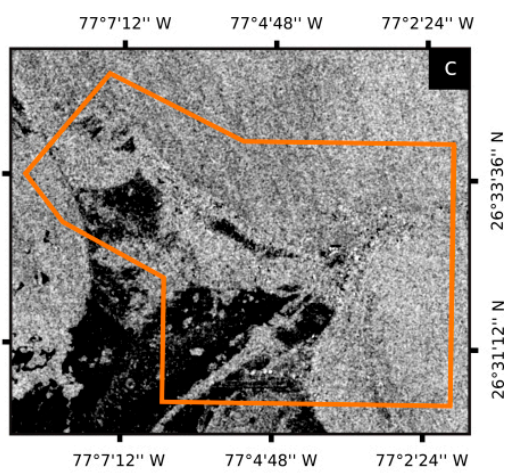

NDR

Figure 6. SAR and NDR images for Marsh Harbour area. (a) SAR image from 21 August 2019; (b) SAR image from 2 September 2019; (c) NDR.

Despite the lack of field measurements, the NDR thresholding is based on the numerous videos from the media. Numerous helicopter flights were organized after the event. Images of key areas or buildings from 3 September helped us to define the correct threshold. The threshold value of -0.2 was chosen.

The overall accuracy of the classification reaches $85 \%$. However, the high proportion of false positives and false negatives gives a low Kappa index value of 0.12. According to this value, the predicted flooded area shows a low level of agreement with the flooding detected by EMS.

The surface detected as impacted by flooding is far greater with NDR analysis $\left(10.2 \mathrm{~km}^{2}\right)$ than with EMS mapping $\left(1.2 \mathrm{~km}^{2}\right.$ ) (Table 3). Many differences can easily be identified. For instance, all the wetlands located on the southern part of the perimeter are not mapped as flooded by EMS but appear impacted. Another example is clearly visible in the urban area, where a discontinuity of the flooded area is detected by EMS while the NDR detects the whole of this flooded surface (Figure 7). 
Table 3. Confusion matrix. Data in square kilometers ${ }^{1}$.

\begin{tabular}{cccc}
\hline Observed by EMS Copernicus & \multicolumn{3}{c}{ Predicted by NDR } \\
\hline & Flooded & Non-flooded & Total EMS \\
Flooded & 0.8 & 0.4 & 1.2 \\
Non-flooded & 9.4 & 55.4 & 64.8 \\
Total predicted & 10.2 & 55.8 & 66 \\
\hline
\end{tabular}

${ }^{1} \mathrm{P}_{0}=0.85$, Kappa index $=0.12$, none to slight agreement.

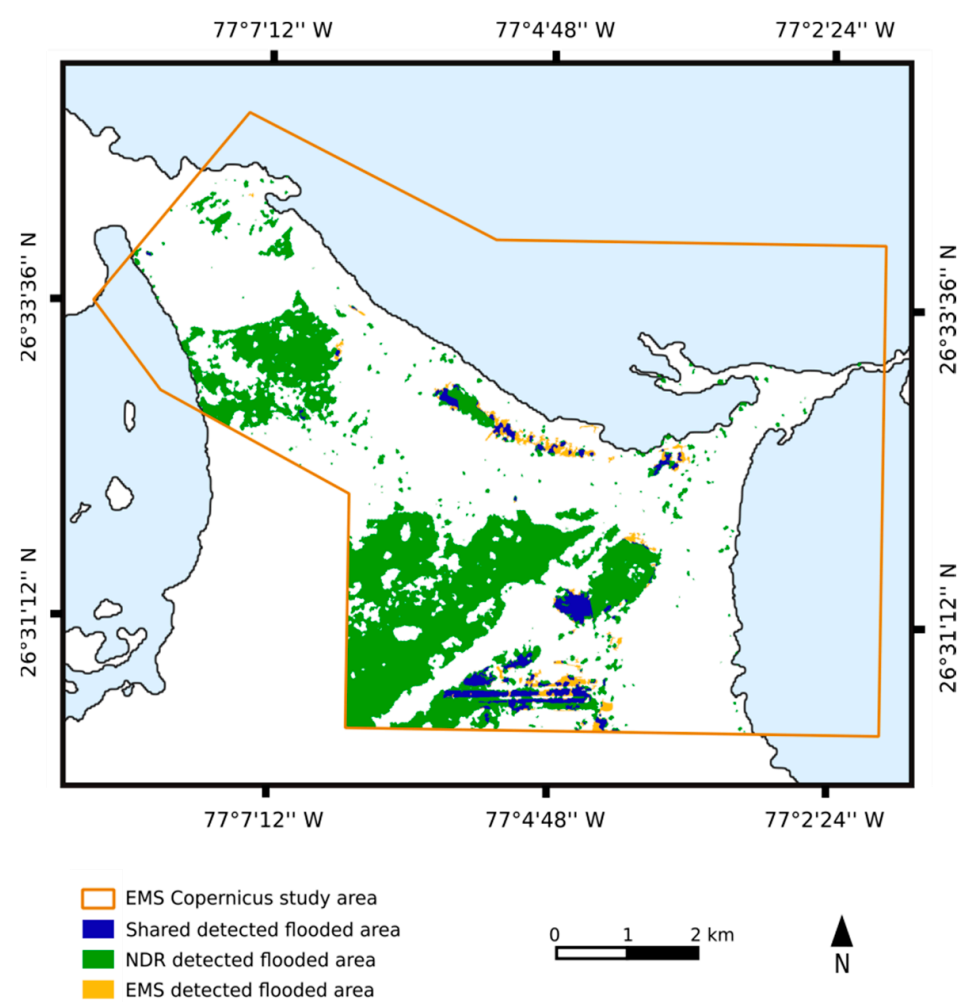

Figure 7. Flood detection comparison between NDR and EMS Copernicus in Marsh Harbour area.

\subsection{Beira}

In the Beira area, the NDR is calculated from images of 18 February, 25 days before the event, and 20 March, five days after the event (Figure 8). Choosing the nearest date possible enables only the flooding caused by the event to be detected.

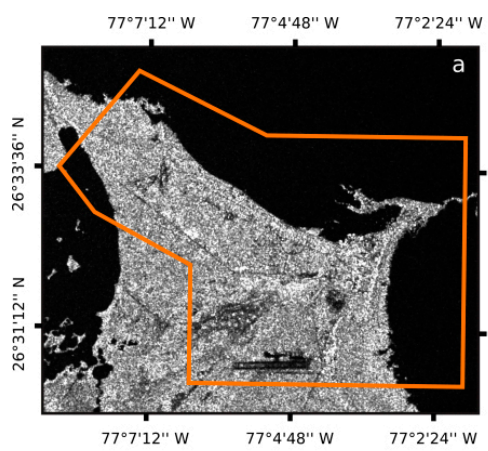

EMS Copernicus EMSR 385 study area

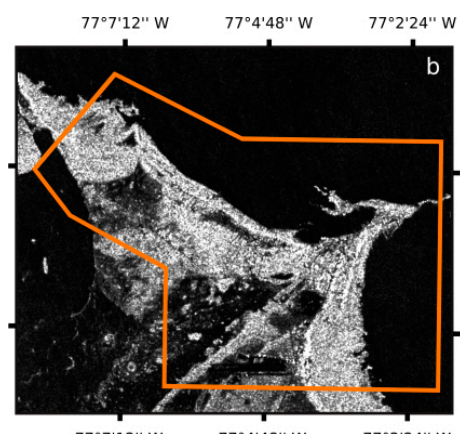

$77^{\circ} 7^{\prime} 12^{\prime \prime} W \quad 77^{\circ} 4^{\prime} 48^{\prime \prime} W \quad 77^{\circ} 2^{\prime} 24^{\prime \prime} W$

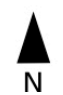

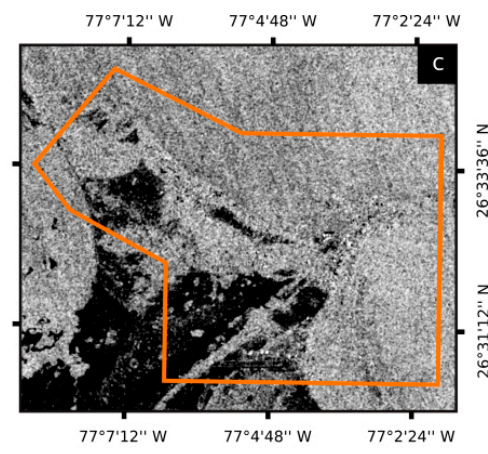

NDR

Figure 8. SAR and NDR images for Beira area. (a) SAR image from 18 February 2019; (b) SAR image from 20 March 2019; (c) NDR. 
We applied the same threshold of -0.2 in the area. The difference between results from NDR and EMS mapping is less significant this time, with 75\% of the EMS-detected flooded area detected by the NDR method.

The overall accuracy of the classification reaches 95\% this time, with a Kappa index of 0.75 (Table 4). This demonstrates strong agreement between the flooded areas predicted by NDR and the EMS detection.

Table 4. Confusion matrix. Data in square kilometers ${ }^{1}$.

\begin{tabular}{cccc}
\hline Observed by EMS Copernicus & \multicolumn{3}{c}{ Predicted by NDR } \\
\hline & Flooded & Non-flooded & Total EMS \\
Flooded & 71.6 & 23.5 & 95.1 \\
Non-flooded & 19.2 & 728.7 & 747.9 \\
Total predicted & 90.8 & 752.2 & 843 \\
\hline${ }^{1} \mathrm{P}_{0}=0.95$, Kappa index & $=0.75$, substantial agreement.
\end{tabular}

As is visible on the comparison map (Figure 9), certain patches of flooded areas are only detected by EMS. Some of these surfaces are objects corresponding to permanent water, such as reservoirs or aquacultures.

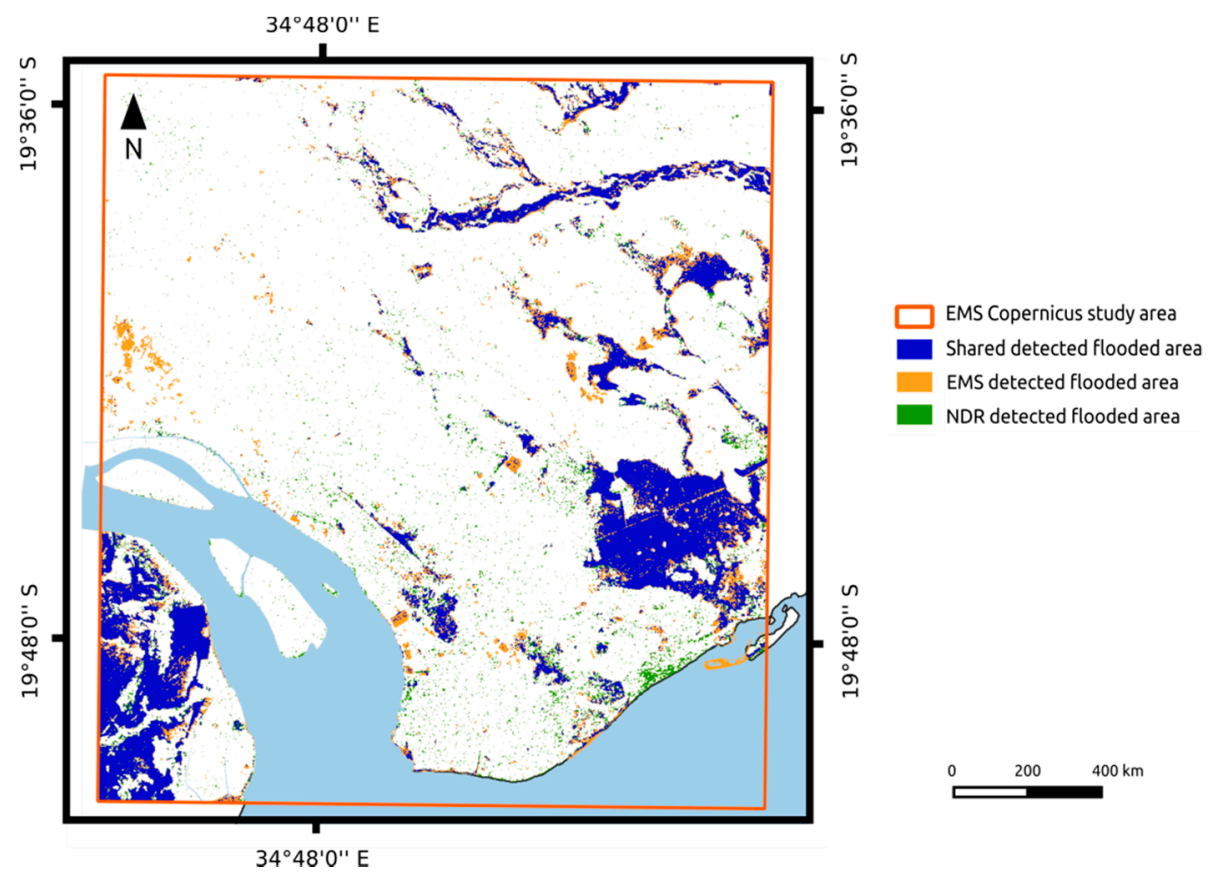

Figure 9. Flood detection comparison between NDR and EMS Copernicus in Beira area.

The first example is a reservoir, dry at the reference date of EMS mapping. As Figure 10c shows, it can be full of water. This reservoir was detected as already containing water on the first Sentinel-1 image and so is not considered to be flooded.

The same analysis can be made with the aquaculture plot in Figure 11. Traces of water can be observed in blue tones in the image from satellite imagery company Maxar Technologies, signifying that this plot can be under water, as visible in the pre-event Sentinel-1 image. 

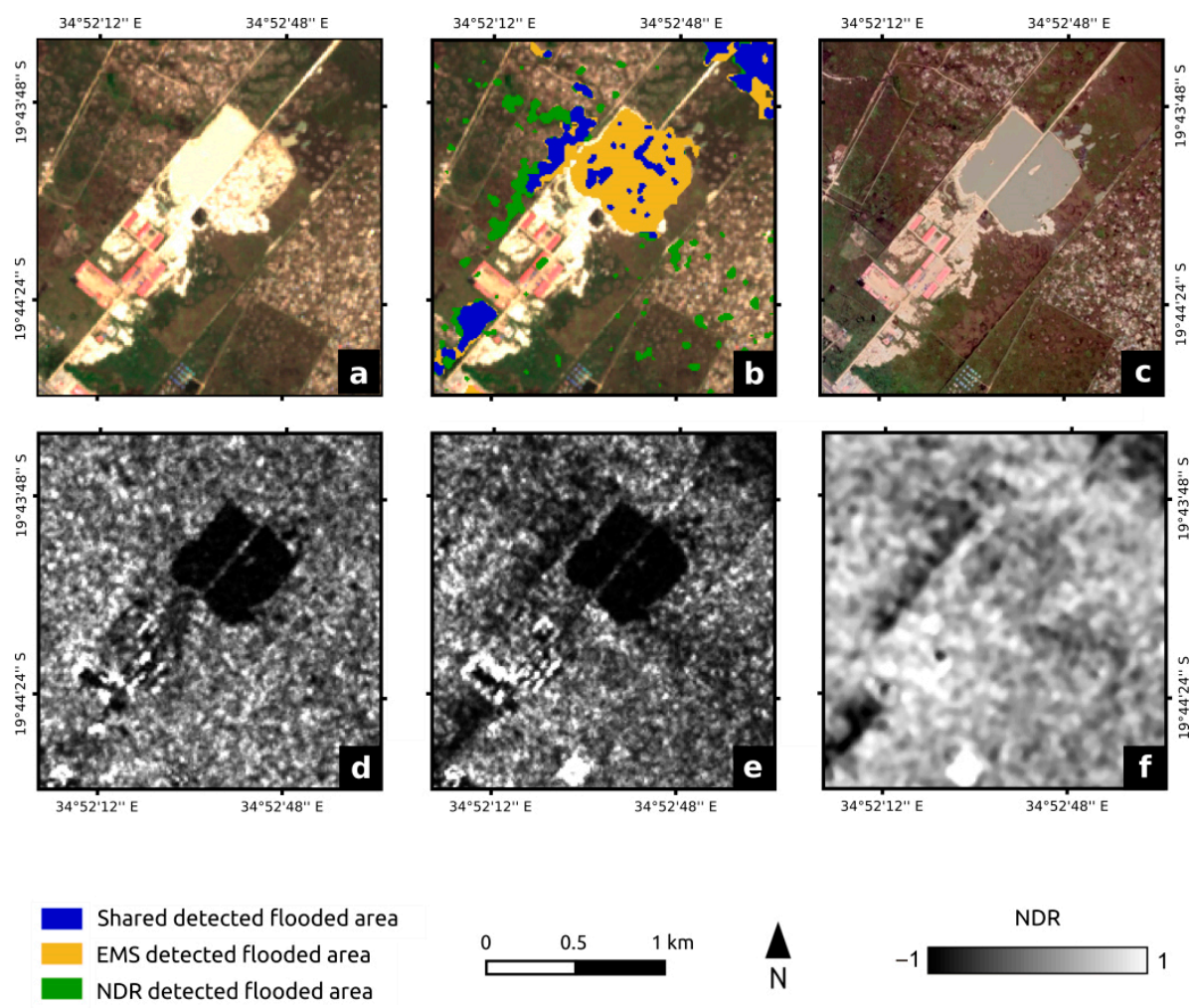

Figure 10. EMS Copernicus Beira basin false detection. (a,b) Sentinel-2 image from 2 December 2018; (c) Maxar 27 February 2019 (Google Earth); (d) Sentinel-1 from 18 February 2019; (e) Sentinel-1 from 20 March 2019; (f) NDR.
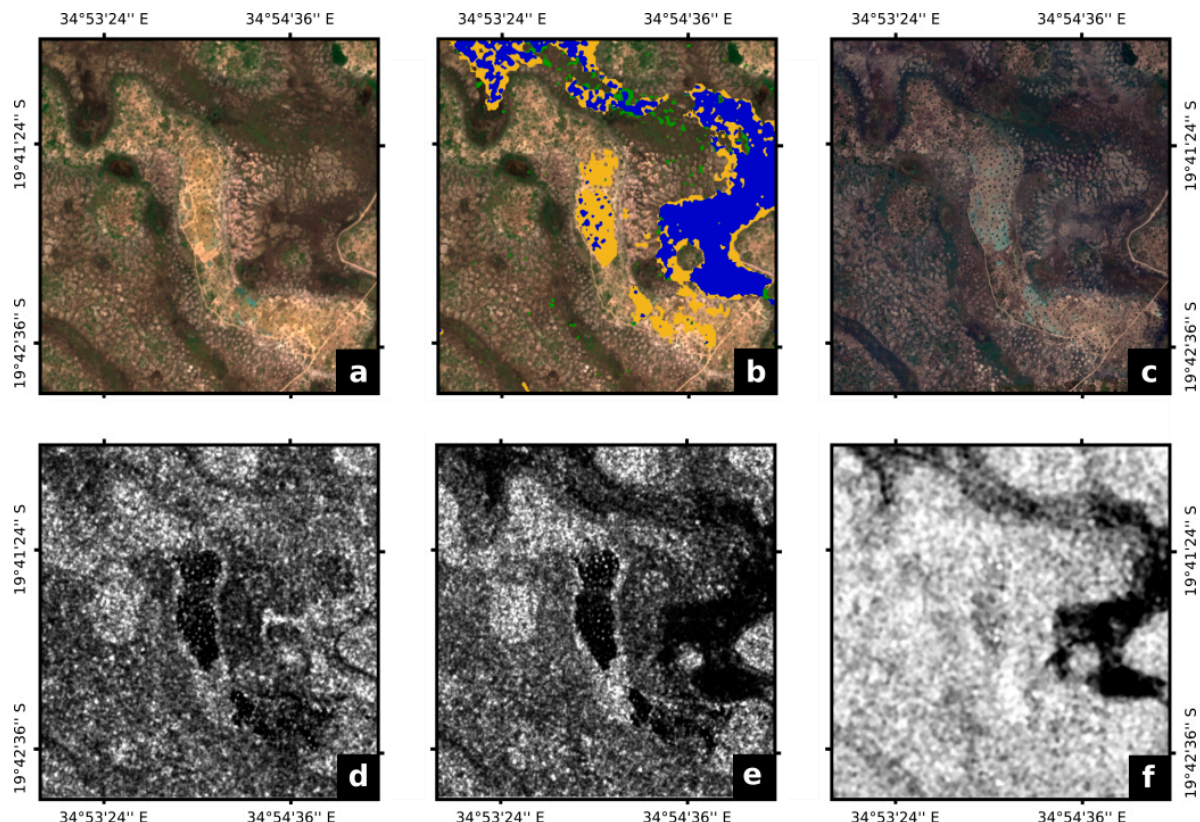

Shared detected flooded area EMS detected flooded area nDR detected flooded area
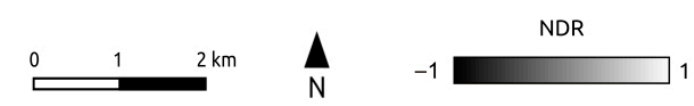

Figure 11. EMS Copernicus Beira aquaculture false detection. (a,b) Sentinel-2 image from 2 December 2018; (c) Maxar 27 February 2019 (Google Earth); (d) Sentinel-1 from 18 February 2019; (e) Sentinel-1 from 20 March 2019; (f) NDR. 


\subsection{Time-Series Processing}

\subsubsection{Marsh Harbour}

A dataset of four images has been proceeded to map the return of water level on Marsh Harbour. The surface of flooded area decreases from $10.2 \mathrm{~km}^{2}$ on 2 September 2019 , to $3.3 \mathrm{~km}^{2}$ on 14 September 2019. That represents a decrease of $70 \%$ in almost two weeks (Table 5). The urban flooded area situated on the northern coast recedes rapidly in one week. Wetlands as the southern part of the study area take more time to return to their initial state (Figure 12).

Table 5. Evolution of flooded area in Marsh Harbour between 2 and 14 September 2019. Data in square kilometers.

\begin{tabular}{cccc}
\hline Date & 2 September 2019 & 8 September 2019 & 14 September 2019 \\
\hline Flooded area & 10.2 & 8.4 & 3.3
\end{tabular}

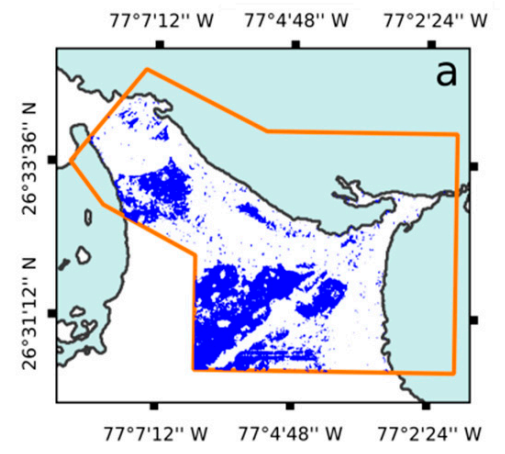

EMS Copernicus study area NDR detected flooded area

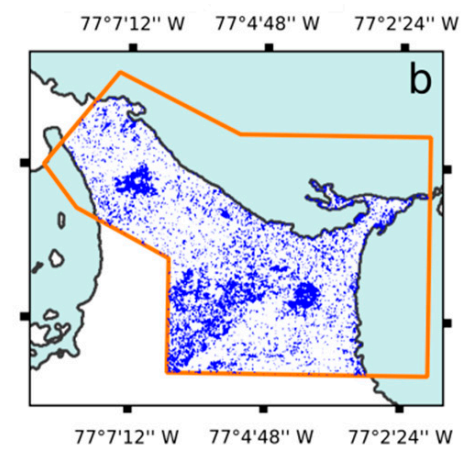

$\Delta$
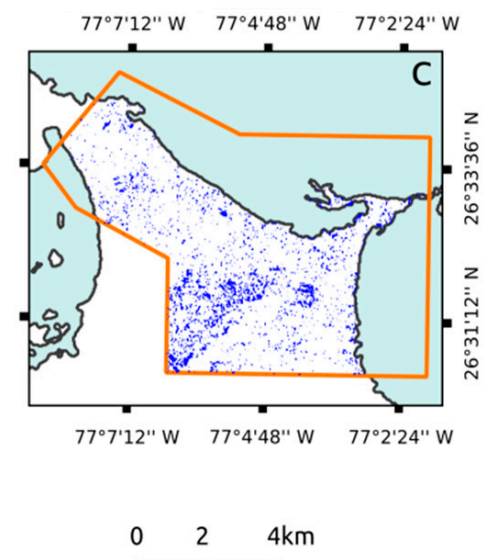

Figure 12. Map of flood extend in Marsh Harbour area between 2 September 2019 and 14 September 2019. (a) 2 September 2019; (b) 8 September 2019; (c) 14 September 2019.

\subsubsection{Beira}

On Beira study area, a dataset of five images have been processed to map flooded areas with NDR algorithm. The results highlight the rapid retreat of the main water bodies within the 12 first days (Figure 13). Water level in the main flooded areas in the southwest and east sectors can be seen decreasing, despite quite noisy results for the last two dates. Between March 20 and 26, the observed water surface area decreased by 50\% (Table 6). We then observe a stabilization and then a return of water on some areas, for example, southeast of the last image in wetlands.

Table 6. Evolution of flooded area in Beira between 20 March and 7 April 2019 from Sentinel-1 NDR processing. Data in square kilometers.

\begin{tabular}{ccccc}
\hline Date & 20 March 2019 & 26 March 2019 & 1 April 2019 & 7 April 2019 \\
\hline Flooded area & 90.8 & 46.1 & 65.2 & 65.4 \\
\hline
\end{tabular}



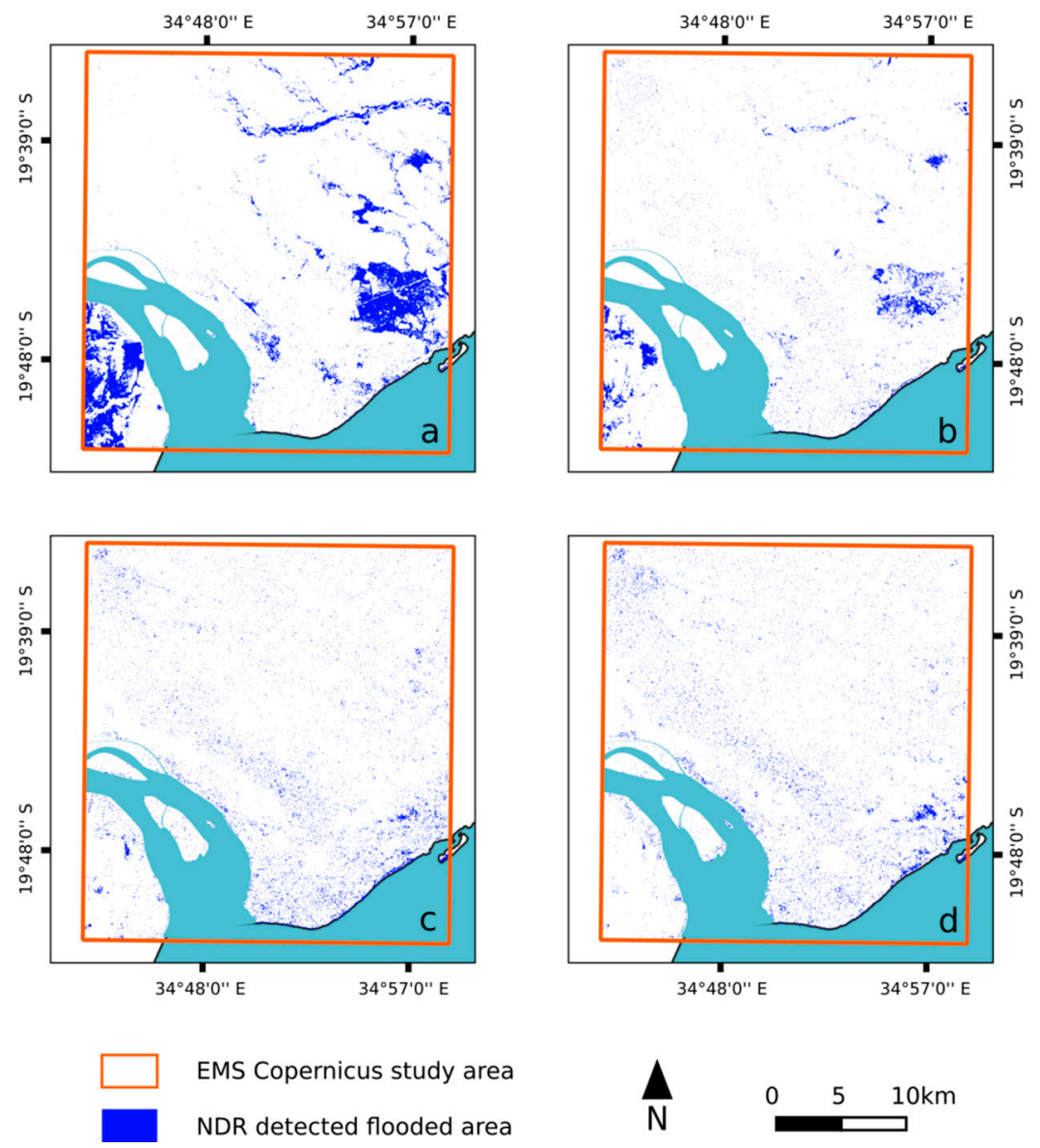

Figure 13. Map of flood extent in Beira area between 20 March 2019 and 7 April 2019. (a) 20 March 2019; (b) 26 March 2019; (c) 1st April 2019; (d) 7 April 2019.

\section{Discussion}

Remote sensing has become an essential tool for disaster monitoring and management. Meteorological events make the use of optical images difficult as cloud cover can be considerable. The use of radar images insensitive to weather conditions thus becomes more relevant. New platforms and sensors provide frequent and highly spatially resolved images. The processing chain presented in this study has been developed around the freely available Sentinel- 1 imagery. It provides an easy-access tool for processing radar data, often considered to be very complex, in order to detect and map flooded areas in a cyclonic context. The use of S1-Tiling, designed to pre-process large amount of Sentinel-1 data, enabled us to focus on a large time period for flood monitoring and resilience.

The Bahamas case-study was used as a calibration site. Highly impacted by Hurricane Dorian in September 2019, the island of Great Abaco is an ideal study site, especially thanks to the considerable media coverage that took place after the event. This mainly photographic and video data used as ground truth data enabled the threshold value for the NDR to be set empirically. However, the flood surface detected by the EMS rapid mapping products and the proposed method is quite different, with more detection with NDR. This difference can be explained by different factors. First, the imagery data is different, with very high-resolution optical data for Ems rapid mapping against 10-m resolution SAR for the proposed method. Moreover, the date of the EMS imagery is four days after the event, compared to one day with NDR. While the results are different, they are not totally inconsistent with two-thirds of the EMS Rapid Mapping total area detected by NDR.

Aware of that, we applied the same threshold value to the region of Beira, highly impacted by Cyclone Idai. In this case, as for the Bahamas, the most visible impacts were the large flooded areas 
that were of interest to map and follow. In this case, our results are fairly similar to those of EMS Rapid Mapping. Indeed, the same post-event Sentinel-1 image was used for both methods. Many differences in detection are due to the presence of semi-permanent water zones in the area, which were for most probably not present in the pre-event optical image used by EMS. These semi-permanent water zones can locally produce over-detections of the flooded area if the image used as reference is taken long before, during a drier season for example. One of the advantages of the NDR is to use two Sentinel-1 radar products for pre- and post-event references, which can closely surround the date of the cyclone, thus eliminating from detection areas already in water Nonetheless, the purpose of the proposed methodology and EMS Copernicus rapid mapping is very different. EMS Copernicus creates products in order to help for crisis management and therefore has a strong time constraint. The product we propose will be used to assess the costs of flooding and environmental resilience in the longer term.

In both study sites, a speckle noise on the data remains noticeable, impacting automatic flood detection by the algorithm. In the current state of the methodology, it is difficult to discriminate between background noise and actual floods for the smaller areas. One of the objectives of this work was to assess the capacities of S1-Tiling for time-series processing in multiple environments and locations, without any changes in the algorithm. S1-Tiling uses the Quegan multi-temporal speckle filter to produce the final denoised images. One of the prospects for improving our methodology will be to compare the results with different advanced multi-temporal speckle filters [48,49], either a modified Quegan filter [50], or the Lee sigma based multi-temporal, which both give interesting results.

There are several studies whose objective is the creation of a processing chain based on Sentinel-1 for detection of change or water surfaces. Most are water surfaces classifications using algorithms of a range of complexity. Huang et al. [51] and Pham et al. [52] use the random forest method and a neuronal network respectively. Both algorithms are trained with Landsat images and the SRTM permanent water surface for Huang et al. [51]. These methods are dependent on optical images for training models. Bioresita et al. [9] use a classification method that is apparently accurate but also very complex with numerous pre-treatment, modeling and post-treatment steps. Furthermore, the accuracy assessment using F-measure or F-Score cannot be compared with our results because it does not take into account true negatives. Li et al and Amitrano et al. [23,24] studies offer a comparison with other different methods and globally obtained well detection of water. Although fully automated, the first method underline that the selection of reference image can be time consuming (several hours might be required). The second provided an unsupervised framework for S1 flood mapping combining a textural analysis with a fuzzy classification on GRD amplitudes and an object based image analysis. Even if the detection seems particularly accurate, the question of reproducibility of an object-oriented method on other geographical areas can be raised. These studies are undoubtedly interesting and a future comparison with other methods such as those presented in Amitrano [24] would be constructive.

The studies by Twele et al. [22] and Muro et al. [53] are more comparable to our work but for different reasons. Like us, Twele et al. [22] offer a fully functional automatic processing chain but still using one-to-one image classifications. The proposed chain and the work of Muro et al. [53] are very similar even if the algorithms are different. What is really at stake here is change detection and not water surface classification. Indeed, our work aims to calculate an indicator based on the comparison of two images taken over a short period of time, one just before the event and the other just after. The algorithm is based on S1-omnibus, which is a variance analysis method. This method can be considered as robust in terms of results and the use of a statistical indicator. However, as reported in the paper, this method detects any type of change without being able to define its nature. While the NDR does not allow the real nature of the change to be defined either, it can provide information on its direction: smoother or more rugged.

Although improvements can still be made to it, this processing chain under active development proposes an innovative and robust solution compared to other interesting chains developed elsewhere. It has the benefit of being based on a non-supervised method, being easy to use for non-expert users, and using free Sentinel-1 images. 


\section{Conclusions}

The algorithm presented in this paper permits Sentinel-1 data processing for detection of flood impacts from the download to the final product thanks to S1-tiling for the pre-treatment and NDR for flood detection.

Cyclonic seasons give rise to clouds and atmospheric disturbance. Less impacted by these than optical imagery, Sentinel-1 data are a reliable solution for flood detection during these periods. Even if the cloud cover is considerable, SAR images can be mobilized and potentially exploited sooner after an event than optical images. This reactivity leads to better flood assessment, when flooding reaches its maximum in terms of impacted areas.

NDR is a simple method for implementing automated flood detection, enabling accurate detection in different areas. With pre-event images closest to the event date, it is possible to prevent detection of objects that were already in water such as reservoirs, basins or paddy fields. Only the true event's impacts are detected, leading to greater accuracy.

In this study, the automated chain showed its effectiveness at two study sites, for specific events and during a short time period after the cyclones. However, it can be transposed to any place in the world which makes it possible to quickly and efficiently process a large time-series of pre- and post-event images, in order to evaluate impacts and resilience of the study site.

The processing algorithms are still under active development as multiple improvements could still be made. One of the short-term prospects would be the integration of other multi-temporal despeckling methods into the chain for a better noise filtering as it is still sensitive in the results. Finally, algorithms and source code of the entire processing chain will be published online, in an open source policy.

Author Contributions: Conceptualization, S.R. and G.P.; Methodology, T.C.; Supervision, G.P.; Writing-original draft preparation, C.A.; Writing—review and editing, C.A., R.J., T.C., P.M., C.R. and G.P. All authors have read and agreed to the published version of the manuscript.

Funding: This work is supported by the EU Interreg project Renovrisk-Impact funded by the European Union, the IRD, and Reunion Regional Council.

Acknowledgments: The authors thank Olivier Hagolle from the CESBIO and Thierry Koleck from the CNES for sharing their codes of peps_download and S1-Tiling respectively.

Conflicts of Interest: The authors declare no conflict of interest.

\section{References}

1. The CEOS Database: Catalogue of Satellite Instruments. Available online: http://database.eohandbook.com/ database/instrumenttable.aspx (accessed on 17 December 2019).

2. Joyce, K.E.; Belliss, S.E.; Samsonov, S.V.; McNeill, S.J.; Glassey, P.J. A review of the status of satellite remote sensing and image processing techniques for mapping natural hazards and disasters. Prog. Phys. Geogr. Earth Environ. 2009, 33, 183-207. [CrossRef]

3. Kossin, J.P.; Emanuel, K.A.; Vecchi, G.A. The poleward migration of the location of tropical cyclone maximum intensity. Nature 2014, 509, 349-352. [CrossRef] [PubMed]

4. Climate Phenomena and their Relevance for Future Regional Climate Change. In Climate Change 2013: The Physical Science Basis; Cambridge University Press: Cambridge, UK, 2013; pp. 1-92.

5. Fitchett, J.M.; Grab, S.W. A 66-year tropical cyclone record for south-east Africa: temporal trends in a global context. Int. J. Climatol. 2014, 34, 3604-3615. [CrossRef]

6. Kuleshov, Y.; Fawcett, R.; Qi, L.; Trewin, B.; Jones, D.; McBride, J.; Ramsay, H. Trends in tropical cyclones in the South Indian Ocean and the South Pacific Ocean. J. Geophys. Res. 2010, 115, D01101. [CrossRef]

7. Fitchett, J.M. Recent emergence of CAT5 tropical cyclones in the South Indian Ocean. S. Afr. J. Sci. $2018,114$. [CrossRef]

8. Revilla-Romero, B.; Hirpa, F.; Pozo, J.; Salamon, P.; Brakenridge, R.; Pappenberger, F.; De Groeve, T. On the Use of Global Flood Forecasts and Satellite-Derived Inundation Maps for Flood Monitoring in Data-Sparse Regions. Remote Sens. 2015, 7, 15702-15728. [CrossRef] 
9. Bioresita, F.; Puissant, A.; Stumpf, A.; Malet, J.-P. A Method for Automatic and Rapid Mapping of Water Surfaces from Sentinel-1 Imagery. Remote Sens. 2018, 10, 217. [CrossRef]

10. Martinis, S.; Twele, A.; Voigt, S. Unsupervised Extraction of Flood-Induced Backscatter Changes in SAR Data Using Markov Image Modeling on Irregular Graphs. IEEE Trans. Geosci. Remote Sens. 2011, 49, 251-263. [CrossRef]

11. Sanyal, J.; Lu, X.X. Application of Remote Sensing in Flood Management with Special Reference to Monsoon Asia: A Review. Nat. Hazards 2004, 33, 283-301. [CrossRef]

12. Klemas, V. Remote Sensing of Floods and Flood-Prone Areas: An Overview. J. Coast. Res. 2015, 314, 1005-1013. [CrossRef]

13. Lin, L.; Di, L.; Yu, E.G.; Kang, L.; Shrestha, R.; Rahman, M.S.; Tang, J.; Deng, M.; Sun, Z.; Zhang, C.; et al. A review of remote sensing in flood assessment. In Proceedings of the IEEE 2016 Fifth International Conference on Agro-Geoinformatics (Agro-Geoinformatics), Tianjin, China, 18-20 July 2016; pp. 1-4.

14. Shen, X.; Wang, D.; Mao, K.; Anagnostou, E.; Hong, Y. Inundation Extent Mapping by Synthetic Aperture Radar: A Review. Remote Sens. 2019, 11, 879. [CrossRef]

15. Bovolo, F.; Bruzzone, L. A detail-preserving scale-driven approach to change detection in multitemporal SAR images. IEEE Trans. Geosci. Remote Sens. 2005, 43, 2963-2972. [CrossRef]

16. Gamba, P.; Dell'Acqua, F.; Trianni, G. Rapid Damage Detection in the Bam Area Using Multitemporal SAR and Exploiting Ancillary Data. IEEE Trans. Geosci. Remote Sens. 2007, 45, 1582-1589. [CrossRef]

17. Martinez, J.; Letoan, T. Mapping of flood dynamics and spatial distribution of vegetation in the Amazon floodplain using multitemporal SAR data. Remote Sens. Environ. 2007, 108, 209-223. [CrossRef]

18. Cian, F.; Marconcini, M.; Ceccato, P. Normalized Difference Flood Index for rapid flood mapping: Taking advantage of EO big data. Remote Sens. Environ. 2018, 209, 712-730. [CrossRef]

19. Zhang, S.; Lu, H. Learning Texture Classifier for Flooded Region Detection in SAR Images. In Proceedings of the IEEE International Conference on Computer Graphics, Imaging and Visualization (CGIV'05), Beijing, China, 26-29 July 2005; pp. 93-98.

20. Gong, M.; Li, Y.; Jiao, L.; Jia, M.; Su, L. SAR change detection based on intensity and texture changes. ISPRS J. Photogramm. Remote Sens. 2014, 93, 123-135. [CrossRef]

21. Ouled Sghaier, M.; Hammami, I.; Foucher, S.; Lepage, R. Flood Extent Mapping from Time-Series SAR Images Based on Texture Analysis and Data Fusion. Remote Sens. 2018, 10, 237. [CrossRef]

22. Twele, A.; Cao, W.; Plank, S.; Martinis, S. Sentinel-1-based flood mapping: a fully automated processing chain. Int. J. Remote Sens. 2016, 37, 2990-3004. [CrossRef]

23. Li, Y.; Martinis, S.; Plank, S.; Ludwig, R. An automatic change detection approach for rapid flood mapping in Sentinel-1 SAR data. Int. J. Appl. Earth Obs. Geoinformation 2018, 73, 123-135. [CrossRef]

24. Amitrano, D.; Di Martino, G.; Iodice, A.; Riccio, D.; Ruello, G. Unsupervised Rapid Flood Mapping Using Sentinel-1 GRD SAR Images. IEEE Trans. Geosci. Remote Sens. 2018, 56, 3290-3299. [CrossRef]

25. Zhang, Y.; Wang, S.; Wang, C.; Li, J.; Zhang, H. SAR Image Change Detection Using Saliency Extraction and Shearlet Transform. IEEE J. Sel. Top. Appl. Earth Obs. Remote Sens. 2018, 11, 4701-4710. [CrossRef]

26. Bayik, C.; Abdikan, S.; Ozbulak, G.; Alasag, T.; Aydemir, S.; Balik Sanli, F. Exploiting multi-temporal Sentinel-1 SAR data for flood extend mapping. ISPRS Int. Arch. Photogramm. Remote Sens. Spat. Inf. Sci. 2018, XLII-3/W4, 109-113. [CrossRef]

27. Weismiller, R.A.; Kristof, S.J.; Scholz, D.K.; Anuta, P.E.; Momin, S.A. Change Detection in Coastal Zone Environments. Photogramm. Eng. Remote Sens. 1977, 43, 1533-1539.

28. Rignot, E.J.M.; van Zyl, J.J. Change detection techniques for ERS-1 SAR data. IEEE Trans. Geosci. Remote Sens. 1993, 31, 896-906. [CrossRef]

29. Gianinetto, M.; Villa, P. Mapping Hurricane Katrina's widespread destruction in New Orleans using multisensor data and the normalized difference change detection (NDCD) technique. Int. J. Remote Sens. 2011, 32, 1961-1982. [CrossRef]

30. Jackson, B.B. Multivariate Data Analysis; The Irwin Series in Marketing; Irwin: Homewood, IL, USA, 1983; ISBN 978-0-256-02848-5.

31. Nielsen, A.; Conradsen, K. Multivariate Alteration Detection (MAD) in Multispectral, bi-Temporal Image Data: A New Approach to Change Detection Studies; Technical University of Denmark: Copenhagen, Denmark, 1997. 
32. Chehata, N.; Orny, C.; Boukir, S.; Guyon, D. Object-based forest change detection using high resolution satellite images. ISPRS Int. Arch. Photogramm. Remote Sens. Spat. Inf. Sci. 2013, XXXVIII-3/W22, 49-54. [CrossRef]

33. Jensen, J.R. Introductory Digital Image Processing: A Remote Sensing Perspective, 4th ed.; Pearson Series in Geographic Information Science; Pearson Education: Glenview, IL, USA, 2016; ISBN 978-0-13-405816-0.

34. Neagoe, V.-E.; Stoica, R.-M. A New Neural Approach of Supervised Change Detection in SAR Images Using Training Data Generation with Concurrent Self-Organizing Maps. In Proceedings of the IGARSS 2018-2018 IEEE International Geoscience and Remote Sensing Symposium, Valencia, Spain, 22-27 July 2018; pp. 4792-4795.

35. Rodríguez, E.; Morris, C.S.; Belz, J.E. A Global Assessment of the SRTM Performance. Photogramm. Eng. Remote Sens. 2006, 72, 249-260. [CrossRef]

36. Landsea, C.W.; Franklin, J.L. Atlantic Hurricane Database Uncertainty and Presentation of a New Database Format. Mon. Weather Rev. 2013, 141, 3576-3592. [CrossRef]

37. Hurricane Dorian Causes Devastation in Bahamas. Available online: https://public.wmo.int/en/media/news/ hurricane-dorian-causes-devastation-bahamas (accessed on 9 January 2020).

38. METEO FRANCE LA REUNION-Alerte cyclonique sur les saisons passées. Available online: http: //www.meteofrance.re/cyclone/saisons-passees/2018-2019/dirre/IDAI (accessed on 9 January 2020).

39. Filipe D.F., L.; Abdoulaye, H.; Mark, M.; Nyree, P.; Jake, B.; John, W.; Sebastien, L.; Firas, J.; Angel, L.A.V. Reducing Vulnerability to Extreme Hydro-Meteorological Hazards in Mozambique after Cyclone IDAI; World Meteorological Organization: Geneva, Switzerland, 2019.

40. Thierry Koleck/S1TemporalSeries|GitLab. Available online: http://tully.ups-tlse.fr/koleckt/s1tiling (accessed on 9 January 2020).

41. Available online: https://github.com/olivierhagolle/peps_download (accessed on 2 January 2020).

42. Quegan, S.; Le Toan, T.; Yu, J.J.; Ribbes, F.; Floury, N. Multitemporal ERS SAR analysis applied to forest mapping. IEEE Trans. Geosci. Remote Sens. 2000, 38, 741-753. [CrossRef]

43. Mishra, B.; Susaki, J. Optical and SAR data integration for automatic change pattern detection. ISPRS Ann. Photogramm. Remote Sens. Spat. Inf. Sci. 2014, II-7, 39-46. [CrossRef]

44. Baghdadi, N.; Bernier, M.; Gauthier, R.; Neeson, I. Evaluation of C-band SAR data for wetlands mapping. Int. J. Remote Sens. 2001, 22, 71-88. [CrossRef]

45. Henry, J.-B.; Chastanet, P.; Fellah, K.; Desnos, Y.-L. Envisat multi-polarized ASAR data for flood mapping. Int. J. Remote Sens. 2006, 27, 1921-1929. [CrossRef]

46. Clement, M.A.; Kilsby, C.G.; Moore, P. Multi-temporal synthetic aperture radar flood mapping using change detection: Multi-temporal SAR flood mapping using change detection. J. Flood Risk Manag. 2018, 11, 152-168. [CrossRef]

47. Cohen, J. A Coefficient of Agreement for Nominal Scales. Educ. Psychol. Meas. 1960, 20, 37-46. [CrossRef]

48. Lukin, V.; Rubel, O.; Kozhemiakin, R.; Abramov, S.; Shelestov, A.; Lavreniuk, M.; Meretsky, M.; Vozel, B.; Chehdi, K. Despeckling of Multitemporal Sentinel SAR Images and Its Impact on Agricultural Area Classification. In Recent Advances and Applications in Remote Sensing; Hung, M.-C., Wu, Y.-H., Eds.; InTech: London, UK, 2018; ISBN 978-1-78923-536-4.

49. Zhao, W. Multitemporal SAR images denoising and change detection-Applications to Sentinel-1 data. Ph.D. Thesis, University Paris-Saclay, Paris, France, 2019.

50. Wegmüller, U.; Santoro, M.; Werner, C. Multi-temporal SAR data filtering for land applications. In Proceedings of the SA Living Planet Symposium, Edinburgh, UK, 9-13 September 2013; p. 5.

51. Huang, W.; DeVries, B.; Huang, C.; Lang, M.; Jones, J.; Creed, I.; Carroll, M. Automated Extraction of Surface Water Extent from Sentinel-1 Data. Remote Sens. 2018, 10, 797. [CrossRef]

52. Pham-Duc, B.; Prigent, C.; Aires, F. Surface Water Monitoring within Cambodia and the Vietnamese Mekong Delta over a Year, with Sentinel-1 SAR Observations. Water 2017, 9, 366. [CrossRef]

53. Muro, J.; Canty, M.; Conradsen, K.; Hüttich, C.; Nielsen, A.; Skriver, H.; Remy, F.; Strauch, A.; Thonfeld, F.; Menz, G. Short-Term Change Detection in Wetlands Using Sentinel-1 Time Series. Remote Sens. 2016, 8, 795. [CrossRef]

(C) 2020 by the authors. Licensee MDPI, Basel, Switzerland. This article is an open access article distributed under the terms and conditions of the Creative Commons Attribution (CC BY) license (http://creativecommons.org/licenses/by/4.0/). 